\title{
O TERMO
}

"LINGUAGEM" EM

MOUNIN E SEUS

PROBLEMAS

TEÓRICOS DA

TRADUÇÃO

Marion CELLI ${ }^{1}$

RESUMO: Este trabalho visa a descrever as impressões iniciais de uma pesquisa de doutorado em andamento cujo objetivo principal é estudar o conceito do termo "linguagem" em textos clássicos sobre tradução, a fim de contribuir para uma perspectiva da atividade de linguagem como alicerce do ato de traduzir (CULIOLI, 1990). O presente artigo tem como foco chamar a atenção para a ex-

\footnotetext{
${ }^{1}$ Doutoranda do Programa de Pós-Graduação em Estudos da Tradução da Faculdade de Filosofia, Letras e Ciências Humanas da Universidade de São Paulo - marion.celli@gmail.com
} 
plicitação conceitual do termo e apresentar o estudo de caso de um dos textos que compõem o corpus de estudo da pesquisa - a clássica obra Les problèmes théoriques de la traduction, do pensador francês Georges Mounin (1963). Tal discussão foi inspirada em nossa participação no X Encontro do Francês, evento anual do Programa de Pós-graduação em Estudos Linguísticos, Literários e Tradutológicos em Francês da Universidade de São Paulo.

PALAVRAS-CHAVE: tradução, linguagem, invariância, línguas, variância.

\section{LE TERME «LANGAGE » CHEZ MOUNIN ET SES PROBLÈMES THÉORIQUES DE LA TRADUCTION.}

RÉSUMÉ : Ce travail veut décrire les premières impressions d'une recherche doctorale dont l'objectif principal est celui de étudier le concept du terme «langage » dans des textes classiques sur la traduction afin de contribuer à une perspective de l'activité de langage comme fondement de l'acte de traduire (CULIOLI, 1990). Cet article a pour but d'attirer l'attention sur la explicitation conceptuelle du terme et présenter une étude de cas sur l'un des textes qui composent notre corpus d'étude - Les problèmes théoriques de la traduction, écrit par le penseur français Georges Mounin (1963). Cette discussion a été inspirée par notre participation à la $X$ Encontro do Francês, événement annuel organisé par la Chaire d'Etudes Linguistiques, Littéraires et Traductologiques en Français de l'Université de São Paulo.

MOTS-CLÉS : traduction, langage, invariance, langues, variance.

\section{O TERMO "LINGUAGEM" NA TRADUÇÃO}

Falar de "linguagem" não é uma tarefa fácil. Sua origem, manifestações e desdobramentos, com explicações não científicas até as teorias atuais mais embasadas, são objeto de reflexão do ser humano há séculos. Suas relações com os conceitos de língua e fala intrigam tanto pesquisadores interessados no funcionamento do cérebro e da mente quanto sociólogos e biólogos que estudam a comunicação e a socialização dos animais. Para alguns, por exemplo, o termo "linguagem" pode designar uma capacidade, como quando se diz que "o homem é dotado de linguagem"; para outros, pode significar os traços comuns a todas as línguas ou, ao contrário, a relação da língua com sua utilização e representação formal. Além disso, muitas línguas possuem apenas uma palavra para designar ambos os conceitos de língua e linguagem, o que torna tal distinção ainda mais sutil. ${ }^{2}$

${ }^{2}$ Como nos casos de language (inglês) e Sprache (alemão), por exemplo. 
Esse panorama tem reflexo direto nos Estudos da Tradução. O surgimento de novas perspectivas de pesquisas sobre tradução na segunda metade do século 20 levou o campo a se distanciar da Linguística, à qual os estudos do domínio se apoiaram inicialmente. Tal distanciamento gerou um gradativo desinteresse dos trabalhos de tradução sobre o estudo da linguagem e das línguas e um desprendimento conceitual da área da Linguística. O termo "linguagem", desse modo, passou a ser usado direta ou indiretamente por estudiosos da tradução de diferentes maneiras, frequentemente em seu sentido mais amplo, como "modo de falar, escrever ou se expressar", o que tem gerado uma ausência de explicitação conceitual que merece ser discutida mais profundamente. A noção de linguagem como atividade cognitiva humana responsável pela construção de significação é fundamental para os Estudos da Tradução, já que ela nada mais é que o alicerce da operação de traduzir (CULIOLI, 1990).

Considerando tal problemática, decidimos realizar uma pesquisa de doutorado que descrevesse o modo como o conceito de "linguagem" se delineia nos textos considerados clássicos da área da tradução com o intuito de observar seus deslizamentos conceituais. Pretendemos, assim, apresentar as reflexões inicias de uma pesquisa que visa a descrever o desenvolvimento do conceito do termo "linguagem" em textos clássicos sobre tradução, a fim de contribuir para uma perspectiva da atividade de linguagem como papel central no ato de traduzir (CULIOLI, 1990).

Em nossa tese, buscamos refletir paralelamente sobre o tema da invariância da linguagem e a diversidade das línguas e dos textos na tradução a partir da leitura e análise de obras de diferentes perspectivas, tais como os empiristas, conforme Mounin (1963), e os estudiosos dos anos 1950 em diante, segundo Nergaard (1995), entre outros autores citados mais abaixo. Pretende-se ainda que nossa investigação possa fornecer a pesquisadores, estudantes e praticantes da tradução um panorama sobre o posicionamento de diversos autores da área sobre a questão da tradução como fenômeno da linguagem para, ao final, propormos uma perspectiva crítico-teórica que colabore para o percurso de conceituação da atividade de tradução.

Tendo como pano de fundo o cenário mais amplo de investigação acima mencionado, neste artigo mostraremos, a título de exemplificação, as primeiras impressões de nossa pesquisa, que se encontra em seu estágio inicial. Fundamentaremos brevemente nossa visão de linguagem e de tradução para descrevermos, em seguida, os resultados do estudo de caso apresentados no X Encontro do Francês, evento anual do Programa de Pós-graduação em Estudos Linguísticos, Literários e Tradutológicos em Francês da Universidade de São Paulo. Tais resultados referem-se ao levantamento das ocorrências do termo "langage" (linguagem) na obra Les problèmes théoriques de la traduction, do pensador francês Georges Mounin (1963) - um dos textos que compõem nosso corpus de estudo. 


\section{LINGUAGEM E TRADUÇÃO: (IN)VARIÂNCIA LINGUÍSTICA}

A base teórica central de nossa pesquisa é a Teoria das Operações Enunciativas (T.O.E.), de Antoine Culioli (1990, 1999a, 1999b). Segundo a T.O.E., a linguagem, "como uma atividade cognitiva de construção e reconhecimento de formas, é responsável pela constituição dos enunciados e pela construção da significação" (ZAVAGLIA, FLORES, 2009, p. 153). Com base em nosso interesse sobre as relações entre tradução e linguagem, Culioli é interessante, principalmente, pela conceituação de uma teoria vinculada a um rigor metodológico único capaz de analisar e explicar as diferenças entre as línguas a partir das operações elementares que as embasam. Para tanto, propõe uma teoria dos observáveis, pautada no texto, que dê conta de uma representação formal que relacione a diversidade de cada situação de enunciação com as operações mentais que antecedem cada ato enunciativo. Trata-se de uma constante articulação epistemológica que permite relacionar a variabilidade e a deformabilidade das mais diferentes línguas às noções primitivas que as fundamentam. Quando o tradutor procura, na língua-alvo, uma estrutura ou determinada palavra correspondente à língua de partida, é possível calcular, ou seja, fazer uma tradução que dê conta de ajustar e reelaborar o jogo categorial, sintático ou morfológico, por exemplo, entre as línguas.

Culioli propõe que somente a partir da análise dos textos é possível observar a rede de fenômenos e funcionamentos que articulam as operações linguageiras ${ }^{3} \mathrm{de}$ uma dada língua. Para tanto, o estudioso propõe a construção de um sistema de representação dividido em três níveis: (I) da linguagem, (II) das línguas e (III) da metalinguagem. É dessa forma que as operações de linguagem, de natureza cognitiva e protagonistas no processo de construção de significados, levou-nos a questionar a relação entre a invariância da linguagem e a variância das línguas no processo de tradução. A tradução torna-se, desse modo, um rico observatório dessa dinamicidade linguística pertencente ao nível II, referente à diversidade das línguas, de acordo com a teoria culioliana.

Para refletirmos sobre a questão da linguagem nos estudos tradutológicos, é difícil não voltarmos a Jakobson (1995) e seu trabalho - clássico nessa área - "Aspectos linguísticos da tradução”. Neste texto, o autor trata da tradução como parte do processo de produção de significado, que exerce papel fundamental na relação entre linguagem e línguas. Mais especificamente, sobre a tradução interlingual, afirma que "a tradução envolve duas mensagens equivalentes em dois códigos diferentes”, o que o leva a concluir que "a equivalência na diferença é o problema principal da linguagem e a principal preocupação da Linguística” (1995 [1959], p. 65). Diferença, dissemelhança e heterogeneidade entre original e tradução têm sido foco de muitos estudos recentes no campo dos estudos tradutológicos. Porém, de que linguagem fala Jakobson? De que equivalência? De que linguística? Benjamin (2001 [1923]), anteriormente, também já discutia tal conceito, definindo-o

${ }^{3}$ Linguageiro - linguagem; linguístico - línguas. 
como uma espécie de essência espiritual, definindo a tradução como elemento reformulador contínuo e complementar que permite a uma dada língua fornecer a outra algo que antes não lhe era particular. Os estudos pós-estruturalistas, por outro lado, veem a linguagem como elemento determinante da experiência humana consciente e inconsciente, a partir da qual se constitui a atividade de tradução, que implica a figura do sujeito.

Tais visões chamam brevemente a atenção para esse elemento que possibilita a significação, a compreensão, a decifração e, consequentemente, a tradução. Mounin (1963), Nergaard (1995) e Steiner (2005), a partir de amplos trabalhos sobre questões de linguagem e a prática de tradução mostram, com base em uma série de pensadores de diversas áreas envolvidas no processo tradutório, a complexidade do tema e a importância da investigação filosófica sobre o "significado do significado" (STEINER, 2005). Afinal, a tradução

está formal e pragmaticamente implícita em cada ato de comunicação, na emissão e na recepção de cada um e de todos os modos de significar (...). Assim, os meios e problemas estruturais e operacionais essenciais do ato de traduzir estão integralmente presentes nos atos de fala, de escrita ou de codificação pictórica no interior de qualquer língua dada. A tradução entre línguas diferentes é uma implementação particular de uma configuração e modelo fundamentais do dizer humano mesmo lá onde ele é monoglota. (STEINER, 2005, p.14).

Consideramos a tradução, assim, como "uma construção parafrástica dinâmica, cuja base de sustentação é a linguagem" (ZAVAGLIA, 2004, p. 105-106), de modo que não vemos a tradução como geradora de unidades equivalentes fixas, mas de correlações dinâmicas que variam de acordo com as particularidades co(n)textuais de cada forma traduzida (CELLI, 2012). Dessa forma, embora sempre haja o estabelecimento de analogias, cremos não ser possível garantir uma dependência total entre original e tradução. É nesse contexto que, “devido ao caráter transcategorial das palavras, um verbo em uma língua não terá como correspondente noutra língua necessariamente um verbo" (ZAVAGLIA, CELLI, 2010, p. 236). Com base nas questões levantadas, pode-se dizer que nossa proposta baseia-se fundamentalmente no argumento de que, se o ato de traduzir é possível, é porque, acima de tudo, a atividade linguageira é a mesma para todas as línguas (DUCARD, NORMAND, 2006, p. 308). 


\section{DEFININDO O CORPUS DE ESTUDO}

Nossa pesquisa de doutorado, por se tratar de um estudo sobre teoria de tradução, tem como corpus essencialmente obras teóricas provenientes de grandes frentes da tradução, segundo as classificações de Mounin (1963) e Nergaard (1995).

Primeiramente, faremos um levantamento de grande parte dos autores chamados por Mounin de empiristas (1963, p.11-12),ou seja, aqueles que não falam da tradução de maneira sistemática, mas relatam, nos prefácio das obras traduzidas, suas impressões e opiniões a respeito da experiência de traduzir, tais como Cícero, Horácio, São Jerônimo, Dante, Erasmo, Étienne Dolet, Joachim du Bellay, Amyot, Lutero, La Motte-Houdar, Montesquieu, Mme.Dacier, Rivarol, Pope, Chateaubriand, Paul-Louis Courier, Goethe, Schlegel, Schopenhauer, Humboldt, Leconte de Lisle, Mallarmé, Bérard, Bédier, Mazon, Valéry Larbaud, Croce e Gide. Após a leitura desses textos, repertoriaremos as visões sobre o termo "linguagem" nesses autores. Para tanto, teremos como ponto de partida as antologias bilíngues sobre os clássicos da tradução desenvolvidas pela Universidade Federal de Santa Catarina (2001, 2004, 2005, 2006), a coletânea organizada por André Lefevere (1977) Translating Literature: the German tradition e a compilação de Miguel Ángel Vega (1994) Textos clásicos de teoría de la traducción.

Em seguida, realizaremos o mesmo procedimento de levantamento, leitura, pesquisa e avaliação crítica dos autores chamados por Nergaard (1995) de primeira, segunda e terceira geração. A primeira se ocupa da frase como unidade de pesquisa, cujos estudos privilegiam os textos não literários e a cultura do texto a ser traduzido, com estudiosos como Wilss, Mounin, Nida, Catford e Jakobson. A segunda geração já é fundamentada na cultura do tradutor e passa a ter o texto como unidade de estudo, colocando em evidência, dessa vez, os textos literários, com autores como Holmes, Lambert, Van den Broeck, Toury, Even-Zohar, Meschonnic, Ladmiral, Berman, Lotman, Paz e Eco. Finalmente, a terceira geração desmistifica a dicotomia entre frase e texto, texto literário e texto não literário, elegendo a interculturalidade como objeto de reflexão, com pesquisadores como Quine, Gadamer, Venuti, Lefevere e Bassnett (ZAVAGLIA, 2002). Para isso, teremos como última integrante de nosso corpus de pesquisa a obra de referência The translation studies reader (2012), de Lawrence Venuti.

Contextualizada nossa pesquisa de maneira mais ampla, trataremos a seguir do estudo de caso apresentado na ocasião do X Encontro de Francês, referente à discussão e análise das ocorrências do termo "linguagem" na clássica obra sobre tradução Les problèmes théoriques de la traduction (1963) de Georges Mounin. Iniciamos, assim, nossa pesquisa com Mounin e seu trabalho sobre a (im)possibilidade da prática da tradução. 


\section{PRIMEIROS RESULTADOS: ESTUDO DE CASO}

Georges Mounin pode ser considerado um dos autores-chave de nosso levantamento, uma vez que, conforme mencionado acima, levaremos em conta, em nossa investigação, os autores por ele citados como os "empiristas da tradução". O quadro a seguir traz as informações gerais da obra e é um exemplo de como contextualizaremos os demais textos futuramente analisados, especificando o autor, título da obra, ano de publicação, contexto histórico na qual está inserida e tendência teórica sobre tradução:

Tabela 1 : Dados gerais de Les problèmes théoriques de la traduction (MOUNIN, 1963).

\begin{tabular}{|c|c|c|c|c|}
\hline Autor & $\begin{array}{l}\text { Título da } \\
\text { obra }\end{array}$ & $\begin{array}{c}\text { Ano de } \\
\text { publicação }\end{array}$ & $\begin{array}{c}\text { Contexto his- } \\
\text { tórico }\end{array}$ & $\begin{array}{l}\text { Tendência } \\
\text { teórica sobre } \\
\text { tradução }\end{array}$ \\
\hline $\begin{array}{l}\text { Georges } \\
\text { MOUNIN }\end{array}$ & $\begin{array}{l}\text { Les pro- } \\
\text { blèmes théo- } \\
\text { riques de la } \\
\text { traduction }\end{array}$ & 1963 & $\begin{array}{c}1^{\text {a }} \text { Geração se- } \\
\text { gundo a classi- } \\
\text { ficação de Ner- } \\
\text { gaard (1995) }\end{array}$ & $\begin{array}{c}\text { Em busca de } \\
\text { uma Ciência da } \\
\text { Tradução }\end{array}$ \\
\hline
\end{tabular}

Em linhas gerais, Mounin discute a escassez de estudos teóricos sobre a tradução, antes apenas vinculada a outras áreas do conhecimento, mostrando os benefícios que os avanços em Linguística trouxeram para a área. Elenca, então, diversas vertentes que ora levam a uma impossibilidade da tradução, como aquelas focadas na equivalência formal, estrutural e sintática, ora à sua possibilidade, como aquelas baseadas na universalidade das formas de conhecimento e de pensamento e que validam a comunicação (inter)linguística.

Em toda obra, há 206 ocorrências do termo "langage" (linguagem), sendo quase a sua maioria em contextos de referência a outros estudos e posicionamentos dos mais diversos autores que refletiram sobre os aspectos levantados por Mounin em sua investigação sobre os problemas teóricos da tradução. A análise do conceito de linguagem deu-se inicialmente a partir de seus comentários acerca das vertentes escolhidas e de sua posterior crítica a tais obstáculos na conclusão de seu trabalho.

Dentre todas as 206 ocorrências do termo, apenas $25 \%$ representam a visão de Mounin propriamente dita. Todas as outras fazem menção aos inúmeros pensadores lembrados ao longo do texto, especialmente em citações diretas ou paráfrases. Mostraremos a seguir, portanto, os trechos mais representativos em que lemos de fato a voz de Mounin referindo-se ao termo "langage" (linguagem). As citações abaixo contêm as ocorrências selecionadas, as quais foram transcritas em francês - língua original de Les problèmes théoriques de la traduction de 1963 -, seguidos de suas traduções em português em nota, de acordo com a tradução de Heloysa de Lima Dantas, na edição de Os problemas teóricos da tradução de 1975. 
O livro é dividido em seis partes e em cada uma delas Mounin demonstra preocupação com os estudos focados nas "estruturas da linguagem", defendendo a tradução como uma Ciência da Linguagem e como uma atividade voltada para as "operações de linguagem"4:

L'observation du comportement des langues dans des situations de contact, à travers les phénomènes d'interférence (« et leurs effets sur les normes de chacune des deux langues exposées au contact ») offre une méthode originale pour étudier les structures du langage. (MOUNIN, 1963, p. 4$)^{5}$

Si donc la nomination des couleurs est tellement différente selon les langues, il ne sera pas possible de mettre en cause la diversité des expériences du monde, ni celle de l'oeil : il s'agira bien du cas, particulièrement typique, où des langues différentes expriment par des structures linguistiques différentes des faits physiques identiques, et prouvent ainsi que la structure du langage ne reflète pas automatiquement celle de l'univers. (MOUNIN, 1963, p. 75)

L'activité traduisante, activité pratique, importante, augmente rapidement dans tous les domaines, ainsi qu'en témoignent les chiffres publiés, particulièrement depuis 1932 par l'Institut de coopération intellectuelle, et depuis 1948 par l'U.N.E.S.C.O. dans son Index Translationum annuel. Il serait paradoxal qu'une telle activité, portant sur des opérations de langage, continue d'être exclue d'une science dulangage, sous des prétextes divers, et qu'elle soit

\footnotetext{
${ }^{4}$ Vale notar que as "operações de linguagem" de Mounin não correspondem às "operações de linguagem" de Culioli. Enquanto para Mounin elas pertencem ao plano da comunicação, para Culioli elas estão ligadas à atividade de representar, referenciar e regular.

5 "A observação do comportamento das línguas em situações de contato, através dos fenômenos de interferência ('e seus efeitos sobre as normas de cada uma das duas línguas expostas ao contato') proporciona um método original para o estudo das estruturas da linguagem" (MOUNIN, 1975, p. 15).

6 "Por conseguinte, embora a denominação das cores varie segundo as línguas, não nos será possível questionar a diversidade das experiências do mundo, nem a do olho: tratar-se-á realmente do caso, particularmente típico, em que línguas diferentes exprimem através de estruturas linguísticas diferentes fatos físicos idênticos, provando assim que a estrutura da linguagem não reflete automaticamente o universo" (MOUNIN, 1975, p. 78-79).
} 
maintenue au niveau de l'empirisme artisanal. (MOUNIN, 1963, p. 7) ${ }^{7}$

O autor chama a atenção para o fato de que "até mesmo os grandes trabalhos [de filosofia da linguagem] recentes de síntese sobre a linguística permanecem mudos a este respeito", ou seja, "quanto à tradução como fenômeno e como problema distinto de linguagem” (1975, p. 22):

Chose plus singulière encore concernant l'étude scientifique de l'opération traduisante : alors que tout traité de philosophie complet se doit d'inclure une théorie du langage, cette dernière n'offre jamais une étude sur la traduction considérée comme une opération linguistique, spécifique et courante cependant, révélatrice peut-être concernant le langage et sans doute la pensée. Les grands ouvrages récents de synthèse sur la linguistique, eux-mêmes, restent muets sur ce point. La traduction, comme phénomène et comme problème distinct de langage, est passée sous silence. (MOUNIN, 1963, p. 11)

O termo "linguagem" é, também, retomado no sentido de modos de falar, quando o estudioso discute a investigação e a busca das unidades semânticas mínimas (1963, p.117-128), como nos trechos "vocabulário da linguagem comum" e "termos da linguagem habitual" vs. "linguagem científica", contrapondo as terminologias técnicas e científicas à "linguagem ordinária”:

Le premier pas de Gardin, qui concerne directement le linguiste, c'est de ne pas utiliser, pour ce classement, le vocabulaire du langage ordinaire, c'est-à-dire le véhicule or-

\footnotetext{
7 "A atividade de tradução, atividade prática, importante, aumenta rapidamente em todos os domínios, como demonstram os números divulgados sobretudo a partir de 1932 pelo Instituto de Cooperação Intelectual, e a partir de 1948 pela UNESCO em seu Index translationum anual. Seria paradoxal se uma atividade desta ordem, voltada para operações de linguagem, continuasse excluída de uma ciência da linguagem, sob diversos pretextos, e mantida ao nível do empirismo artesanal" (MOUNIN, 1975, p. 19).

8 "Fato ainda mais singular, referente ao estudo científico da operação de traduzir: enquanto todo tratado completo de filosofia deve incluir uma teoria da linguagem, esta última jamais apresenta um estudo sobre a tradução encarada como operação linguística, embora específica e corrente, quiçá reveladora com relação à linguagem e sem dúvida com relação ao pensamento. Até mesmo os grandes trabalhos recentes de síntese sobre a linguística permanecem mudos a este respeito. Silencia-se quanto à tradução como fenômeno e como problema distinto de linguagem" (MOUNIN, 1975, p. 22).
} 
dinaire des contenus sémantiques. (MOUNIN, 1963, p. $113)^{9}$

Il faut répéter, ici, que ces traits distinctifs, indiqués au nombre de vingt-deux, sous forme de termes du langage ordinaire, ont, en fait, une définition, métrique ou graphique, c'est-à-dire exprimable, et toujours exprimée, par des mensurations ou par des dessins schématiques, sans aucun recours au langage ordinaire. (MOUNIN, 1963, p. 115116)

(...) bien que le lexique de la botanique, de la zoologie, de la chimie, de toutes les terminologies techniques et scientifiques normalisées soit (comme celui du langage ordinaire) un lexique ouvert, illimité, il n'est structurable que si l'on opère sur des définitions fermées, c'est-à-dire constituées d'un nombre intangible de traits descriptifs pour chaque terme : électron, proton, sulfate de fer, épilobc des montagnes, moteur à courant continu, clavette inclinée creuse sans talon ne sont pas susceptibles, dans leur domaine, de subir les avatars auxquels sont exposés les mots du langage ordinaire, et que décrivent les traités de sémantique, depuis Bréal jusqu'à Ullmann. (...) Tout au plus, le linguiste a-t-il pu remarquer que, sur bien des points, le langage scientifique ou technique issu d'une classification normalisée, tend à substituer son lexique au lexique antérieur de la langue, disons, spontanée. (MOUNIN, 1963, p. 142) ${ }^{11}$

\footnotetext{
9 "O primeiro passo de Gardin, que interessa diretamente ao linguista, consiste em não utilizar, para essa classificação, o vocabulário de linguagem comum, isto é, o veículo habitual dos conteúdos semânticos" (MOUNIN, 1975, p. 113).

10 "É preciso repetir aqui que esses traços distintivos, vinte e dois dos quais foram apontados, sob forma de termos da linguagem habitual, têm de fato uma definição, métrica ou gráfica, isto é, suscetível de ser expressa, e sempre expressa, por medidas ou desenhos esquemáticos, sem nenhum recurso à linguagem comum" (MOUNIN, 1975, p. 114).

11 "(...) embora o léxico da botânica, da zoologia, da química, de todas as terminologias técnicas e científicas normalizadas seja (tal como o da linguagem ordinária) um léxico aberto, ilimitado, ele só é estruturável quando operamos sobre definições fechadas, isto é, constituídas de um certo número intangível de traços descritivos para cada termo: elétron, próton, sulfato de ferro, motor de corrente contínua, epilóbio das montanhas, chaveta inclinada oca sem talão não são suscetíveis, em seus respectivos campos, de se sujeitar às metamorfoses a que estão expostas as palavras da linguagem ordinária, e descritas pelos tratados de semântica, de Bréal a Ullmann. (...) Quando muito, ao linguista foi dado observar que, em muitos pontos, a linguagem científica ou técnica decorrente de uma classificação normalizada, tende a substituir pelo seu próprio léxico o léxico anterior da língua, podemos dizer, espontânea" (MOUNIN, 1975, p. 137-138).
} 
Enfin, les analyses précédentes n'ont, à aucun moment, permis de surmonter l'opposition fondamentale entre langage ordinaire et terminologies techniques et scientifiques : l'existence, dans celui-là, l'inexistence dans celles-ci, de valeurs linguistiques spéciales, dites connotations, qui doivent, maintenant, faire l'objet d'un examen quant aux obstacles qu'elles constituent pour une théorie de la possibilité de la traduction. (MOUNIN, 1963, p. 143) ${ }^{12}$

Sobre os obstáculos da tradução, Mounin cita uma série de autores que, contrários à noção de língua como nomenclatura, ou seja, como "língua-repertório", propõem uma definição mais científica sobre o sentido do enunciado linguístico e acabam, entretanto, sustentando a ilegitimidade da tradução. Segundo Saussure, por exemplo, a tradução não pode funcionar de modo satisfatório porque "as palavras não possuem a mesma superfície conceitual em línguas diferentes" (MOUNIN, 1975, p. 36).

Mounin também ressalta a importância das teorias embasadas nas línguas como "visões de mundo" e a preocupação de autores como Whorf, Koerybzki e Martinet com a relação entre linguagem, língua e cultura.Segundo tais estudiosos, o conhecimento de mundo varia de acordo com a experiência de cada comunidade, alterando, consequentemente, o sistema de estruturas e categorias de cada língua, culturalmente ordenadas. Após levantar diversas questões a respeito de línguas e mundos diferentes e sua consequência para a tradução, Mounin questiona a veracidade de pensarmos em um universo modelado primeiramente pela nossa linguagem:

Est-il vrai que nous pensons dans un univers que notre langage a d'abord modelé? Est-il vrai que nous ne voyons le monde qu'à travers les verres déformants d'une langue particulière, de telle sorte que les images différentes (de la même réalité) que nous obtenons dans chaque langue particulière, ne sont jamais exactement superposables? (...). (MOUNIN, 1963, p. 51) $)^{13}$

\footnotetext{
12 "Finalmente, as análises anteriores não permitiram, em momento algum, vencer a oposição fundamental entre linguagem ordinária e terminologias técnicas e científicas: a existência da primeira, e a inexistência nas últimas de valores linguísticos especiais, ditos conotações que devem constituir agora o objeto de um exame quanto aos obstáculos que elas representam para uma teoria da possibilidade da tradução" (MOUNIN, 1975, p. 138).

13 "Será verdade que pensamos em um universo modelado em primeiro lugar por nossa linguística? Será verdade que só vemos o mundo através das lentes deformantes de uma língua particular, de tal forma que as imagens diferentes (da mesma realidade) que obtemos em cada língua particular nunca podem ser exatamente superpostas?" (MOUNIN, 1975, p. 56).
} 
Les inventaires illimités reflètent, eux, la séparation capitale entre la linguistique considérée comme un système de formes, et les significations de ces formes : la séparation capitale entre les structures limitées du code constitué par le langage, et les structures illimitées de notre découverte, de notre expérience, et de notre connaissance, éternellement inachevées, du monde. Les inventaires illimités du lexique reflètent un passage continuel de la structure acquise du langage à la structure de l'expérience jamais achevée que nous faisons du monde; puis l'incorporation des nouvelles expériences du monde dans une structuration légèrement modifiée du langage (en sa partie sémantique au moins). (MOUNIN, 1963, p. 138) $)^{14}$

$\mathrm{Si}$, d'autre part, on admet avec Whorf et Korzybzki que notre langage fabrique notre pensée pour nous, qu'il y a, par conséquent, - suivant rigoureusement la structure de chaque langue, - des structures de pensée différentes, il est évident que les produits de ces structures de pensée sont, eux aussi, différents, c'est-à-dire que chaque langue a sa conception du monde, son idéologie sous-jacentes (...) (MOUNIN, 1963, p. 68) ${ }^{15}$

Como vimos acima, a relação entre linguagem, pensamento e língua é constantemente levada em consideração e é, diversas vezes, objeto de reflexão. Na maior parte dos casos, Mounin se utiliza dos posicionamentos de outros estudiosos para, enfim, posicionar-se com seus questionamentos sobre linguagem e tradução. O autor chama a atenção ainda para a noção da conotação e a posição de outros estudiosos a respeito de sua definição, concluindo:

Mais ce qui intéresse la théorie de la traduction c'est que les connotations, où qu'on les classe et de quelque façon qu'on

\footnotetext{
14 "Os inventários ilimitados refletem, por sua vez, a separação capital entre a linguística, considerada como sistema de formas, e as significações dessas formas: a separação capital entre as estruturas limitadas do código constituído pela linguagem, e as estruturas ilimitadas de nossa descoberta, de nossa experiência, e de nosso conhecimento, eternamente inacabados, de nosso mundo. Os inventários ilimitados do léxico refletem uma contínua passagem da estrutura adquirida da linguagem para a estrutura da experiência jamais concluída que fazemos do mundo; em seguida, a incorporação das novas experiências do mundo numa estruturação levemente modificada pela linguagem (pelo menos em sua parte semântica)" (MOUNIN, 1975, p. 134).

15 “Se, por um lado, admitirmos com Whorf e Korzybski, que a linguagem fabrica para nós o nosso pensamento, e que existem consequentemente estruturas de pensamento diferentes rigorosamente de acordo com a estrutura de cada língua - é evidente que os produtos dessas estruturas de pensamento também são, por sua vez, diferentes; vale dizer, cada língua tem a sua concepção do mundo, sua ideologia subjacentes (...)." (MOUNIN, 1975, p. 71).
} 
les nomme, font partie du langage, et quïl faut les traduire, aussi bien que les dénotations. (MOUNIN, 1963, p. $166)^{16}$

Trata, em seguida, de uma das objeções fundamentais feitas à possibilidade da tradução, a corrente de pensamento conhecida como "solipsismo linguístico"17. De acordo com os defensores dessa visão, a linguagem não é capaz de transmitir o que se passa em nosso pensamento.

Né comme une intuition sur le langage, grossi philosophiquement par système, le solipsisme linguistique ne s'est jamais soumis à la vérification de l'analyse linguistique, et n'a jamais suivi les progrès de cette analyse. Or celle-ci, depuis bientôt un demi-siècle, a renouvelé complètement la description du langagecomme outil de communication. (MOUNIN, 1963, p. 172)18

Após tecer as considerações acima, Mounin examina o paradoxo de tal intraduzibilidade: "como, por que e até que ponto as diferentes línguas se comunicam entre si, a despeito de todas as razões que nos levariam a temer o contrário?" (1975, p. 190). O autor elenca, por sua vez, sempre com base em estudos complementares, a possível existência de uma propriedade fundamental da linguagem comum a todas as línguas, resumindo a "operação de tradução" como "um caso particular do aprendizado da comunicação" (1975, p. 241). Em resumo:

Comme le postulat de l'unité de l'esprit humain a longtemps dominé, la thèse de la possibilité de la traduction dominait elle aussi de manière empirique; et la thèse de l'impossibilité de la traduction se rencontrait comme une vue théorique, une espèce de paradoxe à la fois difficile à démontrer, et difficile à réfuter. Cela explique sans doute pourquoi le développement d'une attitude scientifique sur

\footnotetext{
16 "Mas o que interessa à teoria da tradução é que as conotações, onde quer que sejam classificadas, e seja qual for o nome que recebam, fazem parte da linguagem, e que é preciso traduzi-las, assim como as denotações" (MOUNIN, 1975, p.158).

17 Segundo tal proposta, "a própria linguagem é incapaz de estabelecer a comunicação dos homens entre si, nem mesmo a comunicação unilíngue" (1963, p.162), de modo que o significado de cada enunciado baseia-se na experiência individual, o qual não pode ser traduzido para outra experiência individual; em outras palavras, nenhum sujeito pode ter a experiência de outro sujeito (MORA, 1994).

18 "Tendo surgido como uma intuição sobre a linguagem, filosoficamente avolumado por sistema, o solipsismo linguístico nunca se submeteu à verificação da análise linguística e jamais acompanhou os progressos dessa análise. Ora, há quase meio século, essa análise renovou completamente a descrição da linguagem como instrumento de comunicação" (MOUNIN, 1975, p. 164).
} 
ces problèmes a pris surtout la forme d'une critique de la thèse dominante : contre la conviction naïve que la communication linguistique - et par conséquent la communication inter-linguistique -, était une espèce de faculté innée, de propriété bio-physio-psychologique commune à tous les hommes, comme la vue ou l'ouïe, la linguistique a multiplié les preuves que le langage est une institution plus visiblement qu'une faculté. Les critiques de la notion traditionnelle de signification, la théorie des champs sémantiques, celle des «visions du monde » différentes, celle des « civilisations » multiples et peut-être étanches les unes aux autres, ont accumulé les preuves que « nous pensons un univers que notre langage a d'abord modelé ». Chaque langue contient, préfabriqué, impose à ses locuteurs une certaine manière de regarder le monde, d'analyser l'expérience que nous avons du monde. (MOUNIN, 1963, p. 271-272) ${ }^{19}$

O conceito de "operação de tradução" em Mounin prioriza, assim, o plano da comunicação, esta última entendida como transferência de conteúdo. É importante ressaltar que, em nosso trabalho ${ }^{20}$, fazemos referência ao termo "operações" no sentido culioliano. Na T.O.E. a expressão "operação enunciativa” culioliana designa as

operações que são responsáveis pela constituição dos enunciados na medida em que constroem a significação pela atribuição de valores referenciais. $O$ termo operação não é dado, mas construído. Isso significa que as formas organizadas que o materializam remetem a operações de constituição do valor referencial. (FLORES, 2009, p. 180)

\footnotetext{
19 "Como o postulado da unidade do espírito humano predominou durante muito tempo, a tese da possibilidade da tradução também predominou de maneira empírica; e a tese da impossibilidade da tradução era tida como uma concepção teórica, como uma espécie de paradoxo, ao mesmo tempo dificilmente demonstrável e dificilmente refutável. Fica assim explicado, sem dúvida, por que motivo o desenvolvimento de uma atitude científica com relação a esses problemas adotou sobretudo a forma de uma crítica à tese dominante: para contrariar a ingênua convicção de que a comunicação linguística - e consequentemente a comunicação interlinguística - constituía uma espécie de faculdade inata, de propriedade biofisiopscicológica comum a todos os homens, como a vista e o ouvido, a linguística multiplicou as provas de que a linguagem é mais visivelmente uma instituição que uma faculdade. As críticas à noção tradicional de que significação, a teoria dos campos semânticos, a das "visões do mundo" diferentes, a das "civilizações" múltiplas e talvez estanques umas para com as outras, acumularam as provas de que "nós pensamos um universo que fora antes modelado pela nossa linguagem". Cada língua contém, pré-fabricada e impõe a seus falantes uma determinada maneira de encarar o mundo, de analisar a experiência que dele temos" (MOUNIN, 1975, p. 246247).

${ }^{20}$ Tese em andamento.
} 
A partir dos trechos acima, nota-se uma considerável variedade conceitual do termo "linguagem", utilizado, nos contextos mencionados, como designação, verbalização, expressão, exteriorização, modo de fala e sistema.

\section{CONSIDERAÇÕES FINAIS}

Todos os sentidos a que se refere "langage" (linguagem) observados nos contextos apresentados na seção anterior colaboram para o próprio pensamento de Mounin sobre a relação entre linguagem e tradução, mesmo que, como pudemos ver, as ocorrências do termo "linguagem" sejam, na maioria das vezes, referentes a outras vertentes linguísticas que embasam, (in)diretamente, a visão de tradução defendida pelo autor. Pode-se dizer que Les problèmes théoriques de la traduction é um rico exemplo de como o termo "linguagem" participa tanto explicita, quanto implicitamente, das discussões e reflexões de Mounin sobre tradução.

Ainda que iniciais, as impressões descritas no presente artigo talvez possam indicar que a aproximação dos Estudos da Tradução à Linguística, no período de Mounin, colabore para o uso do termo "linguagem" em seu conceito mais específico e especializado e que o distanciamento das áreas favoreça o seu uso de modo mais aberto e geral. Quais as consequências dessa diferença de uso? Elas serão sentidas nas abordagens e teorias mais recentes sobre tradução? É o que resta observar e descrever nas próximas etapas de nosso trabalho, uma vez que as reflexões sobre linguagem têm muito a contribuir para o melhor entendimento do processo em que se dá a prática da tradução.

\section{REFERÊNCIAS BIBLIOGRÁFICAS}

BENJAMIN, W. [1923] “A tarefa - renúncia do tradutor”. In: HEIDERMANN, W. (org.). Clássicos da teoria da tradução - Antologia Bilíngue / Alemão - Português, vol. 1. Florianópolis: NUT, 2001, pp. 188-215.

CELLI, M. Um estudo de marcas adversativas do português à luz de uma abordagem lexicográfica bilíngue diferencial (português-francês e portuguêsinglês): o caso de mas, porém, contudo, todavia e entretanto. 2012. 256 f. Dissertação de mestrado. Universidade de São Paulo/FAPESP, São Paulo.

CULIOLI, A. Pour une linguistique de l'énonciation: opérations et représentations. v.1. Paris: Ophrys, 1990. 
. Pour une linguistique de l'énonciation: formalisation et opérations de repérage. v.2. Paris: Ophrys, 1999a.

. Pour une linguistique de l'énonciation: domaine notionnel. v.3. Paris: Ophrys, 1999b.

DUCARD, D; NORMAND, C. Antoine Culioli: Um homme dans le langage - Originalité, diversité, ouverture. Paris: Ophrys, 2006.

FAVERI, C. B. de; TORRES, M. C. (orgs.).Clássicos da teoria da tradução - Antologia Bilíngue / Francês - Português, vol. 2. Florianópolis: NUT, 2004.

FLORES, V. N. Operação enunciativa Culioli. (Verbete). In: FLORES, Valdir; BARBISAN, L. B.; FINATTO, M. J. B.; TEIXEIRA, M. (orgs.). Dicionário de linguística da enunciação. 1. ed. São Paulo: Editora Contexto, 2009.

FURLAN, M. (org.). Clássicos da teoria da tradução - Antologia Bilíngue / Renascimento, vol. 4. Florianópolis: NUT, 2006.

GUERINI, A.; ARRIGONI, M. T. (orgs.). Clássicos da teoria da tradução Antologia Bilíngue / Italiano - Português, vol. 3. Florianópolis: NUT, 2005.

HEIDERMANN, W. (org.). Clássicos da teoria da tradução - Antologia Bilíngue / Alemão - Português, vol. 1. Florianópolis: NUT, 2001.

JAKOBSON, R. [1959] Aspectos linguísticos da tradução. In: Linguística e comunicação. Tradução Izidoro Blikstein e José Paulo Paes. São Paulo: Cultrix, p. 63-72, 1995.

LEFEVERE, A. Translating literature: the German tradition.Assen: Van Gorcum, 1977.

MOUNIN, G. Les problèmes théoriques de la traduction. Paris: Editions Gallimard, 1963.

. Os problemas teóricos da tradução. Tradução Heloysa de Lima Dantas. São Paulo: Cultrix, 1975.

MORA, J. F. Dicionário de filosofia. vol. 2. São Paulo: Edições Loyola, 1994.

NERGAARD, S. (org.). Teorie contemporanee dela traduzione. Milano: Strumenti Bompiani, 1995. 
STEINER, G. Depois de Babel: questões de linguagem e tradução. Tradução Carlos Alberto Faraco. Curitiba: Editora da UFPR, 2005.

ZAVAGLIA, A. Da invariância da linguagem à variância das línguas: contribuição para a elaboração de uma teoria enunciativa da tradução como um caso particular de paráfrase. 2002. Tese de doutorado. Universidade Estadual Paulista Júlio de Mesquita Filho, Araraquara.

Linguística, tradução e literatura: observando a transformação pela arte. Alfa, São Paulo, 48(1), p. 99-117, 2004.

ZAVAGLIA, A; CELLI, M. "Aplicação do conceito de transcategorialidade ao ensino de francês como língua estrangeira: o caso da marca MAS”. In: VIANA, V; TAGNIN, S. E. O. (org.). Corpora no ensino de línguas estrangeiras. São Paulo: Hub Editorial, 2010, p. 235-267.

ZAVAGLIA, A; FLORES, V. N. Linguagem (3) Culioli. (Verbete). In. FLORES, V.; BARBISAN, L. B.; FINATTO, M. J. B.; TEIXEIRA, M. (org.). Dicionário de linguística da enunciação. 1. ed. São Paulo: Editora Contexto, 2009.

VEGA, M. A. Textos clásicos de teoría de la traducción. Madrid: Cátedra, 1994.

VENUTI, L. The Translation Studies Reader. 3. ed. London e New York: Routledge, 2012. 